\title{
Pirâmides e cones de aprendizagem: da abstração à hierarquização de estratégias de aprendizagem
}

\author{
Pyramids and learning cones: from abstraction \\ to bierarchization of learning strategies
}

\author{
Fábio Luiz da Silva \\ Doutor em História. Professor do Programa de Pós-Graduação em \\ Metodologias para o Ensino de Linguagens e suas Tecnologias da \\ Universidade Norte do Paraná, Londrina, PR - Brasil \\ fls.londrina@yahoo.com.br
}

Fabiane Tais Muzardo

Doutoranda em História. Professora do Curso de Licenciatura em História da Universidade Norte do Paraná, Londrina, PR - Brasil

biumuzardo@yahoo.com.br

Resumo: As pirâmides e cones de aprendizagem são recursos costumeiramente utilizados no meio escolar para defender que as práticas pedagógicas que favorecem a participação mais ativa dos alunos são as mais eficientes. Na maioria das vezes, essas pirâmides e cones são associadas aos estudos de William Glasser e Edgar Dale. Esses pesquisadores, contudo, não criaram uma hierarquia de estratégias mais eficientes, muito menos associaram tais estratégias a porcentagem de sucesso ou insucesso na aprendizagem. Em algum momento essa associação foi realizada e transformou-se, com o tempo, em argumento de autoridade. Tendo em vista essa realidade, o objetivo desse artigo é discutir os usos desses sólidos da aprendizagem, tidos, muitas vezes, como referências para praticas pedagógicas de sucesso.

Palavras-chave: Pirâmide de aprendizagem. Cone de aprendizagem. Práticas pedagógicas.

\begin{abstract}
Pyramids and learning cones are resources commonly used in the school environment to defend that the pedagogic practices that favor the more active participation of students are the most efficient. Most of the time, these pyramids and cones are associated with the studies of William Glasser and Edgar Dale. These researchers, however, did not create a hierarchy of more efficient strategies, much less associated those strategies with the percentage of success or failure in learning. At some point this association was created and became, over time, an argument from authority. In view of this reality, the purpose of this article is to discuss the uses of these learning staples, often referred to as pedagogical practices of success.
\end{abstract}

Keywords: Learning pyramid. Cone learning. Pedagogical practices. 


\section{Introdução}

Realizando uma rápida pesquisa na internet, é possível encontrar centenas de imagens de "pirâmides ou cones da aprendizagem". Essas imagens pressupõem que exista alguma hierarquia nas formas como aprendemos e, em sua maioria, apresentam uma gradação composta por ler, escutar, ver, ver e ouvir, discutir, fazer e ensinar. De acordo com esses modelos, a experiência direta, o uso prático ou o ensino aos outros seriam as formas mais eficazes de aprendizado. Por outro lado, os modos menos eficazes seriam ler e ouvir. Muitas vezes os modelos não se referem à aprendizagem, mas à retenção, o que não é a mesma coisa. Em geral, os diferentes níveis da pirâmide ou dos cones são relacionados a percentuais mais ou menos variáveis. Em alguns casos, as informações são apresentadas em outras formas, como tabelas, gráficos de barras ou gráficos circulares. Grande parte das pirâmides é atribuída a William Glasser, ou, quando se diz "cone da aprendizagem", a Edgar Dale. A partir dessas constatações, o objetivo deste artigo é examinar a difusão desses modelos, demonstrando a ausência de estudos científicos que fundamentem a categorização das formas de aprendizagem ou mesmo de retenção de informação.

Letrud e Hernes (2016) consideram que as pirâmides da aprendizagem são mitos. Segundo esses autores, não se localizaram (caso tenham existido) os estudos empíricos originais que pudessem ter embasado a construção desses modelos, "pelo contrário, as revisões de pesquisas sobre diferentes modalidades de aprendizagem não encontraram aquelas hierarquias nas taxas de retenção" (LETRUD; HERNES, 2016, p. 292) [tradução nossa]. Apesar disso, em uma pesquisa no Google, obtêm-se mais de 380 mil resultados para a expressão "pirâmide da aprendizagem" e mais de 400 mil resultados para a expressão "cone da aprendizagem”. Mesmo considerando as inconsistências desses resultados de busca, eles evidenciam a popularidade desse modelo, especialmente fora da academia. No entanto, podemos encontrar as mesmas informações em publicações científicas, como artigos, dissertações e teses. Isso significa que o modelo hierárquico de formas de aprendizagem (ou de retenção) é amplamente aceito, ganhando status de autoridade. Esse fato justifica a necessidade de estudos sobre as origens, difusão e aceitação desses modelos. 


\section{Origens}

Segundo Letrud e Hernes (2016), é difícil localizar a origem precisa dessas propostas. Sem o artifício da imagem de uma pirâmide ou de um cone, foi possível encontrar a ideia de uma hierarquia das formas de aprender, já com percentuais, em uma publicação de 1913. Em um artigo de Frances Haskell a respeito do método Montessori, publicado na revista Journal of Education, de 18 de dezembro de 1913, existe o seguinte trecho [tradução nossa]: "Nós lembramos $20 \%$ do que ouvimos. Lembramos $50 \%$ do que vemos. Lembramos 70\% do que tocamos. Lembramos 90\% do que fazemos" (HASKELL, 1913, p. 638). O autor não faz referência a como obteve essas informações. Subramony et al. (2014) apresentaram uma cronologia dessas tabelas de aprendizagem, revelando diversas versões que surgiram ao longo do século XX. Muitas delas estavam vinculadas a manuais de treinamento ou de instrução, cujos valores também variavam de uma publicação para outra. Por exemplo, Stevens (1921, p. 754) afirmava que "é uma velha máxima da educação que nós lembramos 5\% do que ouvimos e 50\% daquilo que vemos" [tradução nossa]. Podemos encontrar outro exemplo em uma publicação de 1957. Trata-se de um manual de instrução da marinha dos Estados Unidos onde se lê: "Lembramos aproximadamente $10 \%$ do que ouvimos, $20 \%$ do que lemos, $50 \%$ do que vemos e $90 \%$ do que fazemos" (US BUREAU OF NAVAL PERSONNEL, 1957, p. 15) [tradução nossa]. Nesse caso, pelo menos, o autor relativizou os percentuais afirmando que eles seriam aproximados. Em nenhum destes exemplos há qualquer referência às origens dos dados, ou seja, não há indicação alguma sobre pesquisas científicas que pudessem fundamentar tais informações.

O uso da imagem de uma pirâmide ou de um cone de aprendizagem teve início na década de 1940, quando Edgar Dale publicou o livro Audiovisual methods in teaching. Nessa obra, Dale procurou tratar a respeito do ensino por meio de materiais audiovisuais, como rádio e filmes. Segundo Letrud e Hernes (2016), houve uma interpretação equivocada do gráfico em forma de cone que Dale (1946) inseriu em seu trabalho. O que era apenas uma sistematização dos diferentes níveis de abstração (LALLEY; MILLER, 2007), relacionados a diversos métodos de ensino, foi tomado como uma hierarquia das modalidades de aprendizagem, apesar da advertência do próprio Dale (1946), ao afirmar que "as faixas apresentadas pelo cone frequentemente se entrelaçam e se 
misturam umas às outras [...], não haverá confusão entre nosso cone e uma hierarquia ou ordem de classificação dos processos de aprendizagem" (DALE, 1946, p. 47) [tradução nossa]. No cone original, havia os seguintes níveis de abstração: no topo do cone estava Verbal Symbols, na sequência, Visual Symbols, Radio - Recordings Still Pictures, Motion Pictures, Exhibits, Field Trips, Demonstrations, Dramatic Participation, Contrived Experiences e, na base, Direct, Purposeful Experiences.

Além das observações já apresentadas a respeito da imagem que Dale (1946) chama de "cone da experiência", deve-se notar que não há qualquer referência a porcentagens vinculadas a cada uma das faixas do cone. Para Lalley e Miller (2007), Dale jamais utilizou a expressão retenção para descrever o resultado de uma experiência de aprendizado e não apresenta números de uma pesquisa empírica; seu cone foi uma construção a partir de estudos teóricos e suas observações pessoais. Então, em algum momento, alguém mesclou a ideia de Dale (1946) às porcentagens que já eram populares e criou a primeira pirâmide da aprendizagem. É difícil afirmar quem foi o pioneiro, mas Stice (2009), assim como Letrud e Hernes (2016), afirmam que os números mais comuns associados à pirâmide da aprendizagem apareceram pela primeira vez em uma publicação de Treichler, no ano de 1967: "As pessoas geralmente relembram 10\% do que leem, $20 \%$ do que ouvem, 30\% do que veem, 50\% do que ouvem e veem, $70 \%$ do que falam, 90\% do que explicam enquanto fazem algo" (TREICHLER apud LETRUD; HERNES, 2016, p. 293).

No Brasil, a origem mais comum da pirâmide da aprendizagem está associada ao médico psiquiatra William Glasser. A maioria das citações afirma que esse autor teria criado esse modelo na década de 1960. Subramony et al. (2014) afirmam, porém, que Glasser jamais se referiu ou reivindicou crédito por qualquer versão da pirâmide da aprendizagem. Esses autores consideram como falsa qualquer afirmação nesse sentido. A forma como a pirâmide atribuída a Glasser é geralmente apresentada contém a seguinte estrutura: no topo, aprendemos $10 \%$ do que lemos, na sequência, 20\% quando ouvimos, 30\% quando observamos, $50 \%$ quando vemos e ouvimos, $7 \%$ quando discutimos com outros, $80 \%$ quando fazemos e, na base, 95\% quando ensinamos aos outros (A PIRÂMIDE, s/d).

Assim, temos duas tradições historicamente diferentes. Uma que se refere aos percentuais vinculados a diversos níveis de aprendizagem e que, até onde foi possível investigar, é mais antiga; e outra que se utiliza das metáforas do cone e 
da pirâmide para expressar as metodologias mais ou menos apropriadas, numa hierarquia que valoriza a experiência. O cone parece ter sido uma interpretação inadequada do trabalho de Edgar Dale (O CONE, s/d). A pirâmide, por sua vez, ao que tudo indica, é atribuída a William Glasser de modo equivocado.

\section{Os Usos}

A metodologia utilizada para apresentar alguns exemplos de usos, tanto do cone de Dale (1946), quanto da pirâmide de Glasser, foi exploratória, pois há ausência de uma versão que pudesse ser considerada padrão para os modelos de aprendizagem ou retenção. Assim, foram utilizados mecanismos de busca para localizar referências a "cone da aprendizagem" ou "pirâmide da aprendizagem", assim como a Edgar Dale e William Glasser. Primeiro, são apresentados exemplos acadêmicos retirados de artigos, livros e dissertações. Em seguida, aparecem os exemplos retirados de fontes fora da academia, como blogs ou páginas mantidas por professores.

Santos (2010), em sua dissertação de mestrado sobre educação ambiental, utilizou a imagem do que ela chamou "Cone das Experiências" e o atribuiu a Edgar Dale (1946). No entanto, a imagem utilizada por Santos (2010) apresenta algumas diferenças em relação ao cone original. Em Dale (1946) há dez faixas enquanto no cone de Santos (2010) há 11 faixas. Além disso, algumas das faixas foram "atualizadas". Por exemplo, o termo recordings foi substituído por "CD" e Motion pictures foi subdividido em duas faixas por "cinema" e "televisão".

Wangenheim e Wangenheim (2012), em um livro sobre ensino de computação por meio de jogos, apresentaram uma versão do cone de aprendizagem de Dale (1946) com apenas seis faixas, que foram agrupadas em dois tipos de aprendizagem: a superficial e a profunda. Assim, ler, escutar palavras, olhar figuras, assistir a um filme, visitar uma exposição, olhar uma demonstração, ver algo in loco promoveriam apenas uma aprendizagem superficial, enquanto participar de uma discussão, apresentar uma palestra, atuar numa dramaturgia, simular uma experiência real e realizar algo promoveriam uma aprendizagem profunda.

Vaz (2015), em uma dissertação sobre ensino em Educação de Jovens e Adultos, utilizou Edgar Dale para fundamentar sua afirmação de que o aprendizado mais significativo e duradouro seria obtido por métodos que promovem 
a participação direta dos alunos. O cone de aprendizagem que Vaz (2015) utiliza é uma versão mais complexa. O cone aparece invertido e colocado sobre um quadro de três colunas. Na coluna do centro, as faixas de Dale são apresentadas da seguinte forma, organizada da mais eficiente para a menos eficiente: fazendo algo real, simulando uma experiência real, fazendo uma apresentação dramática, conversando, participando de uma discussão, vendo algo feito no local, assistindo a uma demonstração, olhando uma exposição, assistindo a um filme, olhando fotografias, ouvindo palestras, lendo. Na primeira coluna são apresentadas as porcentagens de lembrança que manteríamos após duas semanas. Na terceira coluna é apresentada a natureza do envolvimento, que é dividida em ativa e passiva.

Amarante (2015) utilizou-se do cone de Dale para analisar o ambiente virtual de aprendizagem em uma instituição pública de ensino. Segundo essa autora, os recursos didáticos deveriam estar a serviço da proposta pedagógica dos professores. A imagem é a mesma de Vaz (2015). Em uma dissertação sobre simuladores para treinamento, Reis (2015) também utilizou o cone da aprendizagem atribuído a Edgar Dale. Segundo a autora, o estudo de Dale (1946) teria como objetivo fornecer um modelo intuitivo da eficácia de vários métodos de ensino. Nesse caso, assim como em Wangenheim e Wangenheim (2012), o cone aparece com seis faixas, mas há o acréscimo das porcentagens.

Pereira et al. (2016), em um artigo sobre a inovação na formação continuada de professores, afirmou que a gravação de videoaulas possibilitaria garantir $70 \%$ de retenção do conteúdo se articulasse as dimensões do ler, ver, ouvir e discutir. O fundamento para essa afirmação é atribuído à pirâmide da aprendizagem de Willian Glasser. Rossetti e Bernardi (2017), em um artigo sobre o uso do cinema no ensino médio, utilizaram a pirâmide de Glasser para justificar o porquê assistir a um filme tem vantagem em relação à leitura de um livro. Isto em razão dessa pirâmide indicar que aprenderíamos apenas 10\% do que lemos e 50\% do que vemos e ouvimos.

Umas das referências à pirâmide de aprendizagem, fora do mundo acadêmico, encontra-se na página "Professora Coruja". Trata-se de uma página com sugestões e dicas para professores. Não há indicação clara de quem é responsável pelo site. O texto que acompanha a imagem da pirâmide começa com uma pergunta: "Você sabia que quando ensinamos, é quando mais aprendemos?". Há, portanto, uma ideia a ser defendida e Glasser é invocado para sustentá-la. O texto 
propõe que os alunos aprendem efetivamente quando fazem algo. O texto também afirma que a pirâmide de Glasser é amplamente utilizada no mundo todo. Outra página que utiliza a mesma pirâmide encontrada em "Professora Coruja" é a do Centro de Educação Especial Síndrome de Down. O texto também é o mesmo (VOCÊ, s/d).

Um terceiro exemplo do uso da pirâmide da aprendizagem atribuída a Glasser pode ser encontrado no blog de uma empresa chamada Forleven, que se dedica a apresentar soluções na área da educação para escolas. Segundo a página da empresa, sua missão seria "apoiar educadores e administradores na qualidade do ensino, melhorando notas, frequência e o comprometimento dos alunos com o aprendizado". Assim como na página da "Professora Coruja", o texto inicia com uma pergunta: "Olá, queridos leitores, vocês conhecem a pirâmide de aprendizagem de William Glasser?". Apesar de não haver indicação da fonte, a imagem da pirâmide é a mesma encontrada nos sites anteriores. Nesse caso, a ideia defendida é de que ocorreriam diferentes graus de aprendizagem conforme a forma de estudar dos alunos.

Exemplo de utilização do cone da aprendizagem pode ser encontrado na página da organização Planetapontocom, que promete desenvolver soluções inovadoras na área da educação. Novamente o texto inicia com questionamentos: "Como ensinar crianças e jovens do século XXI? Como fazer com que aqueles conteúdos que julgamos ser importantes sejam compreendidos e assimilados? Como estabelecer o ensino e a aprendizagem neste mundo instantâneo, audiovisual e digital?". Em outras palavras, a hipótese subjacente a essas perguntas é a de que no mundo atual as pessoas aprendem de forma diferente daquelas que viveram no passado e que, portanto, haveria a necessidade de novas formas de ensinar. $O$ texto menciona uma palestra oferecida durante o $21^{\circ}$ Congresso de Educação do Sindicato dos Profissionais em Educação no Ensino Municipal de São Paulo. Segundo o texto, a palestrante teria citado, em sua fala, o cone da aprendizagem de Edgar Dale. A imagem do cone (em inglês, na página) foi usada para fundamentar a ideia de que o aluno aprenderia mais quando é chamado a participar de forma ativa.

Outro exemplo do uso do cone da aprendizagem é a página de uma escola Adventista, em que, apesar de não aparecer a imagem do cone de Dale (1946), a referência a seus escritos é usada para sustentar que o melhor aprendizado é aquele no qual a participação dos alunos é mais ativa. Em outras palavras, 
"quanto mais passivo for o ensino, menor será o aprendizado, e a retenção ficará comprometida". Nesse caso, há referência clara à obra de Edgar Dale.

Vemos, portanto, que os modelos do cone e da pirâmide da aprendizagem são aceitos e amplamente utilizados. Provavelmente um pouco menos na academia, mas intensamente fora dela. 0 que se percebeu é a dificuldade em se localizar o fio da meada que nos levasse claramente à origem dessas metáforas.

\section{Considerações finais}

Os cones e as pirâmides da aprendizagem (ou da experiência) têm sido utilizadas como argumento de autoridade. O uso de perguntas nos textos que acompanham tais figuras tem essa função. Quando se pergunta "você sabia que...?" se está querendo afirmar que existe uma verdade que todos deveriam saber. Em outras palavras, o texto pretende dizer "como assim, você ainda não sabe disso?". O uso de porcentagens também faz parte dessa estratégia. Números deixam os argumentos com aparência de mais científicos. O mesmo se pode afirmar do uso de versões em inglês e das afirmações de que tais modelos são utilizados no mundo todo.

Sendo utilizados como argumentos de autoridade, a ideia geral que se defende é a de que a experiência é mais eficaz para o aprendizado. Assim, a leitura é apresentada como a metodologia menos eficaz, e a prática (o fazer alguma coisa) como a mais eficaz. $O$ ato de explicar algo para alguém também surge como uma maneira melhor de aprender - mas não de ensinar. Nesse sentido, é interessante registrar que existem muitas expressões vinculadas a cada faixa, ou nível, apresentada nos cones e pirâmides. Por isso, no topo do cone de Dale se apresentam "símbolos verbais" como sendo o tipo de experiência menos concreta. Enquanto que, em outros exemplos, a leitura aparece no vértice superior.

Provavelmente, há alguma relação entre a popularização desses modelos e a conquista da hegemonia construtivista no espaço pedagógico. Assim, podemos supor que não seja coincidência que no início do século XX já se valorizasse o fazer, a experiência. John Dewey já afirmava, em 1897, "eu acredito, finalmente, que a educação deva ser concebida como uma reconstrução contínua da experiência" (DEWEY, 2008, p. 91). Dewey desenvolveu essa ideia em obras posteriores sobre educação. 
Nessa mesma perspectiva, encontramos esses modelos sendo utilizados para fundamentar a defesa de que as melhores práticas pedagógicas são aquelas que favorecem a participação dos alunos, pois os alunos de hoje não estariam dispostos a ter aulas expositivas em virtude do acesso ao mundo virtual, apesar de grande parte do conteúdo da internet estar em forma escrita ou visual.

Não foi possível localizar qualquer indicação de pesquisas científicas que pudessem embasar a relação entre as tipologias de aprendizagem, de ensino e os percentuais geralmente expressos. Os modelos são aceitos sem análise crítica, segundo o material analisado para esse estudo. Assim, não há detalhamento de como esses dados foram obtidos, quem foram as pessoas investigadas ou em quais condições a pesquisa (caso exista) foi realizada. Estão ausentes comentários a respeito da generalização dos modelos. Em outras palavras, eles são apresentados como válidos para qualquer idade, classe social, escola, disciplina escolar, cultura, gênero etc. Talvez por isso existam tantas variedades de representações desses modelos, seja em relação aos percentuais, seja em relação às diferentes tipologias utilizadas.

O problema com a aceitação acrítica desses modelos hierarquizantes da aprendizagem é que eles podem estar fundamentando perspectivas pedagógicas diversas. Esse fato pode reduzir, como afirmam Letrud e Hernes (2016), a confiabilidade das pesquisas em educação e em ensino que partem dos pressupostos apresentados pelas metáforas dos cones e das pirâmides. Além disso, muitos professores podem estar utilizando, de forma equivocada, algumas metodologias de ensino acreditando que, segundo esses modelos amplamente difundidos, seus alunos estariam aprendendo $80 \%$ ou $90 \%$ do que eles ensinam.

\section{Referências}

AMARANTE, Daniela Pereira de Moura. Utilização do design instrucional em curso Ead: análise do ambiente virtual de aprendizagem de curso técnico à distância de uma instituição pública de ensino. Projeto de Dissertação (Mestrado Profissional em Sistemas de Informação e Gestão do Conhecimento). 2015. 65f. Universidade Fumec. Belo Horizonte. 2015. Disponível em: <http://www.fumec.br/revistas/sigc/article/view/2912>. Acesso em: 30 maio 2017.

A PIRÂMIDE da aprendizagem de William Glasser. s/d. Disponível em: < http://www.ceesd. org.br/piramide-de-aprendizagem-de-william-glasser/>. Acesso em: 31 maio 2017. 
DALE, Edgar. Audio-visual methods in teaching. New York: Dryden Press,

1946. Disponível em: <http://ocw.metu.edu.tr/file.php/118/dale_audio-

visual_20methods_20in_20teaching_1_.pdf>. Acesso em: 28 maio 2017.

DEWEY, John. My pedagogic creed. In: BOYDSTON, Jo Ann. The early works of John Dewey: 1882-1898. Carbondale: Southern Illinois University Press, 2008.

HASKELL, Frances. A Good word for the Montessori method. In: Journal of Education, 18 dec. 1913, p. 637-638. Disponível em: <https://www.jstor.org/stable/42821420?seq=1\#page_ scan_tab_contents $>$. Acesso em: 25 maio 2017.

LALLEY, James; MILLER, Robert H. Learning pyramid: does it point teachers in the right Direction?. In: Education, v. 128, n. 1, outono, 2007, p. 64-79. Disponível em: <https:// www.researchgate.net/publication/234631764_The_Learning_Pyramid_Does_It_Point_ Teachers_in_the_Right_Direction>. Acesso em 05 jun. 2017.

LETRUD, Kare; HERNES, Sigbjorn. The Diffusion of the learning pyramid myths in academia: na exploratory study. In:Journal of Curriculum Studies, v. 48, n. 3, 2016, p. 291-302. Disponível em: <http:/www.tandfonline.com/doi/full/10.1080/00220272.2015.1088 063>. Acesso em: 25 maio 2017.

O CONE da aprendizagem. s/d. Disponível em: < http://revistapontocom.org.br/materias/ocone-da-aprendizagem>. Acesso em: 31 maio 2017.

PEREIRA, Elisabete M. A et al. Inovação na formação continuada de professores pelo uso de MOOC. In: Anais do VII Encuentro Internacional de Investigadores de Políticas Educativas, 20 a 22 de set. de 2016, p. 185-190. Disponível em: < https://scholar.google. com.br/citations?view_op=view_citation\&hl=pt-BR\&user=IkW-IO4AAAAJ\&citation_for_ view=IkW-IO4AAAAJ:UeHWp8X0CEIC > . Acesso em: 30 maio 2017.

REIS, Renata Lins. Uso de simulador para validação de sistema de segurança de uma planta industrial. Dissertação (Mestrado em Engenharia Industrial). 2015. 81f. Universidade Federal da Bahia. Salvador. 2015. Disponível em: <https://repositorio.ufba.br/ ri/handle/ri/18146>. Acesso em: 30 maio 2017.

ROSSETTI, Regina; BERNARDI, Sueli Fernandes Ferreira. Cinema na educação: uma forma de compreender literatura brasileira no Ensino Médio. In: ECCOM, v. 8, n. 15, jan./jun., 2017, p. 171-186. Disponível em: <http://publicacoes.fatea.br/index.php/eccom/article/view/1716>. Acesso em: 30 maio 2017.

SANTOS, Luana Magda Muniz. Elaboração de material paradidático para educação ambiental com ênfase em atividades lúdicas. Dissertação (Mestrado Profissional em Ensino de Ciências e Matemática). 2010. 88f. Pontifícia Universidade Católica de Minas Gerais. Belo Horizonte. 2010. Disponível em: <http://www.biblioteca.pucminas.br/teses/ EnCiMat_SantosLM_1.pdf. >. Acesso em: 30 maio 2017.

STEVENS, Walter B. Centennial history of Missouri (The Center State): one hundred years in the Union (1820-1921). St. Louis/Chicago: The S. J. Clarke Publishing Company, 1921. Disponível em: <https://babel.hathitrust.org/cgi/pt?id=hvd.hx2zc2;view=1up;seq=782>. Acesso em: 25 maio 2017. 
STICE, James. A Refutation of the percentages often associated with Edgar Dale's cone of learning. In: Annual Conference Proceedings - American Society for Engineering Education, 2009. Disponível em: <https://peer.asee.org/a-refutation-of-the-percentagesoften-associated-with-edgar-dale-s-cone-of-learning.pdf>. Acesso em: 30 maio 2017.

SUBRAMONY, Deepak Prem et al. Timeline of the mythical retention chart and corrupted Dale's cone. In: Educational Technology, v. 54, n. 6, nov./dez., 2014, p. 31-49. Disponível em: <https://docs.google.com/viewer?a=v\&pid=sites\&srcid=ZGVmYXVsdGRv bWFpbnx0aGVjb3JydXB0ZWRjb25lb2ZsZWFybmluZ3xneDo0YTMyNzhjNWMzNWJjNWZm>. Acesso em: 27 maio 2017.

US BUREAU OF NAVAL PERSONNEL. Aviation fire control technician 3. Washigton: United States Government Printing Office, 1957. Disponível em: < https://babel.hathitrust.org/cgi/ pt?id=uc1.b3123748;view=1up;seq=35>. Acesso em: 27 maio 2017.

VAZ, Leandro Marcos Alves. Propondo material de apoio à prática com simuladores no ensino/aprendizagem de eletrostática em EJA. Dissertação (Mestrado em Ensino de Física). 2015. 147f. Universidade de Brasília. Brasília, 2015. Disponível em: <http:// repositorio.unb.br/handle/10482/22002>. Acesso em: 30 maio 2017.

VOCÊ conhece a pirâmide da aprendizagem? s/d. Disponível em: <http://blog.forleven. com/2016/12/01/voce-conhece-a-piramide-de-aprendizagem/> . Acesso em: 31 maio 2017. WANGENHEIM, Christiane Gresse von; WANGENHEIM, Aldo von. Ensinando computação com jogos. Florianópolis: Bookess Editora, 2012.

recebido em 29 ago. 2017 / aprovado em 31 jan. 2018

Para referenciar este texto:

SILVA, F. L.; MUZARDO, F. T. Pirâmides e cones de aprendizagem: da abstração à hierarquização de estratégias de aprendizagem. Dialogia, São Paulo, n. 29, p. 169-179, mai./ago. 2018. Disponível em: < https://doi.org/10.5585/Dialogia.n29.7883>. 
